\title{
Benign isolated sixth nerve palsy in a child- a case report
}

\author{
Ghosh $\mathbf{A}^{1}$, Mukhopadhyay $\mathbf{S}^{2}$ \\ ${ }^{1}$ Dr.Aniruddha Ghosh, Resident, Department of Pediatric Medicine, ${ }^{2}$ Dr. Swapan Mukhopadhyay, Professor, Department \\ of Pediatric Neurology, Both the authors are attached to Institute of Child Health, Kolkata, WB, India.
}

Address for Correspondence: Dr. Aniruddha Ghosh, Institute of Child Health, Kolkata, 11, Dr. Biresh Guha Street, Kolkata, West Bengal, India. E mail ID: aniruddha179@gnail.com

\begin{abstract}
Abducens or sixth cranial nerve innervates lateral rectus muscle and pathology of this nerve results in abduction deficiency of ipsilateral eye. A 6-year-old girl presented with squinting and diplopia. Two weeks ago she suffered from mild cough and cold, likely viral fever. Cerebrospinal fluid analysis and magnetic resonance imaging of brain excluded any underlying disorder of central nervous system. Squint and diplopia subsided on its own within 3 weeks. Apart from serious etiologies benign isolated sixth nerve palsy can occur in children following viral prodrome and usually subsides within weeks without any treatment.
\end{abstract}

Keywords: Abducens nerve palsy, Diplopia, Lateral rectus palsy, Magnetic resonance imaging, Sixth cranial nerve diseases

\section{Introduction}

Abducens/sixth cranial nerve, with its longest subarachnoid course from dorsal pons to lateral rectus muscle, is easily affected by tumour, trauma, hemorrhage, infections, demyelinating conditions, Miller Fisher syndrome, Gradenigo's syndrome and rarely by ophthalmoplegic migraine [1]. So, If a child presents with abducens palsy, it raises the suspicion of an underlying neurological disorders like raised intracranial tension, brain tumour or tuberculous

meningitis in countries like India [1]. If there is no suggestive history or symptoms and signs indicative of one of the five topographical syndromes: brainstem syndrome, elevated intracranial pressure syndrome, petrous apex syndrome, cavernous sinus syndrome or orbital syndrome, the patient can be classified as a case of isolated sixth nerve palsy [2]. But radiological confirmation is important. Here we present the case of a 6 years old girl with isolated right sided sixth nerve palsy resulting in squinting and diplopia.

\section{Case Report}

A 6-year-old girl presented with a sudden onset of double vision. Caregivers denied any recent head or neck trauma, headaches, fevers, or nausea. A review of systems was also negative for any weakness, aphasia, confusion, ataxia, vertigo, or dysphagia.

The patient's past medical history was significant only for upper respiratory infection two weeks ago (probably viral), but she was not taking any medications. There was neither family history of any neurological disorders nor there was any contact history of tuberculosis.

On examination, she had obvious right-sided head position and she was continuously trying to close right eye to avoid diplopia. In extreme rightward gaze the right eye remained in midline while left eye was moving medially in normal manner making the squinting most prominent (Figure 1). The rest of the central nervous system examinations were within normal limits. CSF study was absolutely normal.

Manuscript received: $27^{\text {th }}$ December 2016

Reviewed: $5^{\text {th }}$ January 2017

Author Corrected: $14^{\text {th }}$ January 2017

Accepted for Publication: $20^{\text {th }}$ January 2017 


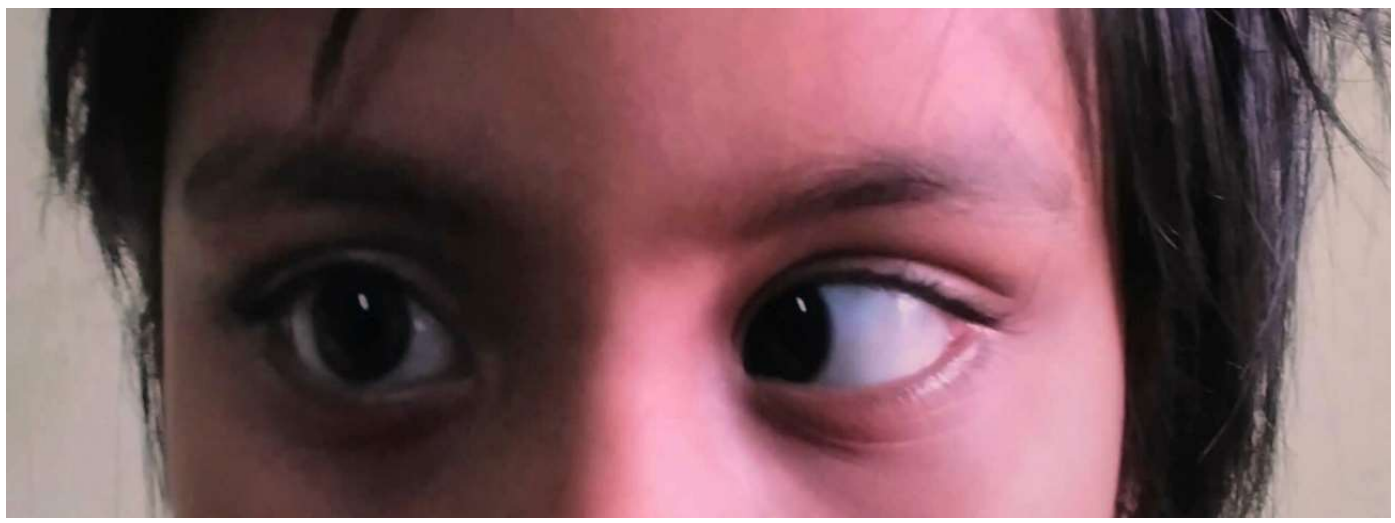

Figure-1: Showing lateral rectus palsy on right side resulting in abduction deficiency of right eyeball in extreme rightward gaze.

A non-contrast and contrast magnetic resonance imaging (MRI) scan of the head and neck confirmed normal brain and orbital structures. Eye check up by a pediatric ophthalmologist revealed absolutely normal acuity of vision, field of vision, colour vision along with normal retina, optic cup and disc. Pupilswere equal, round and reactive to Light with no afferent pupillary defect noted. Hearing examination was also within normal ranges. We thought of benign isolated sixth-nerve palsy in right eye.

We suggested the patching for right eye to prevent a double vision, and followed the patient by one-week interval. At two weeks after the diagnosis, the double vision disappeared and lateral gaze palsy resolved partly. The condition was improved completely at three weeks. The patient is in follow up for last 1 year and didn't relapse again.

\section{Discussion}

There are only a few case series available regarding pediatric sixth nerve palsy. Robertson [3] described tumours of the posterior fossa to be responsible for $39 \%$ of sixth nerve palsy in a cohort of 133 children. On the contrary, Bagheri et al [4] showed $54.4 \%$ of 33 children with sixth nerve palsy were associated with trauma.

A compressive lesion like neoplasm [5] should be suspected if patient develops sixth nerve palsy after trivial trauma to head [6] and thorough work up should be done to rule out skull base tumour. Spontaneous recovery can occur even in neoplastic conditions perhaps due to resorption of bleeding within the tumour, axonal regeneration or host's immune response to neoplasia [7].

Isolated abducens palsy has been reported after vaccination (measles, measles-mumps-rubella, diphtheria-tetanus-pertussis vaccines) and some documented infections i.e. Epstein-Barr, cytomegalovirus, varicella, herpes zoster ophthalmicus, Mycoplasma pneumoniae, Chlamydia pneumonia etc [8]. In pediatric population these sixth nerve palsies have been reported to be benign, remitting and sometimes recurrent in nature [9]. "The benign six-nerve palsy" first documented by Knox et al [10] very rarely may occur in children after minor cough and cold. Knox et al. in 1967 reported 12 children with a sixth nerve palsy as their chief presenting feature; 3 patients had otitis media complicated with Gradenigo syndrome, and for the other 9 patients the investigators assumed that the benign palsy was due to preceding viral febrile or upper respiratory illness.

They suspected the nerve palsies were due to viral neuritis. The authors suggested that if there is a history of a preceding febrile illness and if there are no other abnormal neurological signs, normal x-rays of the skull and sinuses, no abnormality in the cerebrospinal fluid, and no response to pharmacological tests for myasthenia gravis, it is reasonable to delay other investigations and keep the child under observation for three to six weeks, when improvement should be starting if he is suffering from this type of benign sixth-nerve palsy.

Azarmina et al [1] suggested that CT and/or MRI investigations should be performed in addition to Knox et al's suggestions and if it cannot be found an underlying etiology, benign six nerve palsy should be thought and the patient should be followed for three to six weeks without any treatment. 
Our patient also improved spontaneously after 4 weeks of follow up without any treatment.

\section{Conclusion}

We suggest that if a child presents with isolated sixth nerve palsy, a thorough clinical history should be taken especially for any preceding viral prodromal illness. Also, it is essential to rule out any serious underlying pathology like demyelinating disorders, malignancy or infection affecting central nervous system.

A multimodality approach involving pediatrician, neurologist and ophthalmologist is crucial in management of such a patient.

Funding: Nil, Conflict of interest: None initiated, Perission from IRB: Yes

\section{References}

1. Azarmina M, Azarmina H. The six syndromes of the sixth cranial nerve. J Ophthalmic Vis Res. 2013 Apr; 8 (2):160-71.

2. Kline LB. Neruro-ophthalmology review manual. 6th ed. Thorofare, NJ: Slack Incorporated, 2007.

3. Robertson DM, Hines JD, Rucker CW. Acquired sixth-nerve paresis in children. Arch Ophthalmol. 1970 May;83(5):574-9.
4. Bagheri A, Babsharif B, Abrishami M, Salour H, Aletaha M. Outcomes of Surgical and Non-Surgical Treatment for Sixth Nerve Palsy. Journal of Ophthalmic \& Vision Research 2010;5(1):32-7.

5. Depper MH, Truwit CL, Dreisbach JN, Kelly WM. Isolated abducens nerve palsy: MR imaging findings. AJR Am J Roentgenol. 1993 Apr;160(4):837-41.

6. Patel SV, Mutyala S, Leske DA, Hodge DO, Holmes JM. Incidence, associations, and evaluation of sixth nerve palsy using a population-based method. Ophthalmology. 2004 Feb;111(2):369-75.

7. Volpe NJ, Lessell S. Remitting sixth nerve palsy in skull base tumors. Arch Ophthalmol. 1993 Oct;111 (10):1391-5.

8. Greco F, Garozzo R, Sorge G. Isolated abducens nerve palsy complicating cytomegalovirus infection. Pediatr Neurol 2006;35(3):229-30. DOI: 10.1016/j. pediatrneurol.2006.03.008.

9. Cohen HA, Nussinovitch M, Ashkenazi A, Straussberg R, Kaushansky A. Benign abducens nerve palsy of childhood. Pediatr Neurol. 1993 Sep-Oct;9 (5):394-5.

10. Knox DL, Clark DB, Schuster FF. Benign VI nerve palsies in children. Pediatrics. 1967 Oct; 40 (4): 560-4.

\section{How to cite this article?}

Ghosh A, Mukhopadhyay S. Benign isolated sixth nerve palsy in a child- a case report. J PediatrRes.2017;4(01): 3537.doi:10.17511/ijpr.2017.i01.07 